\title{
A Rare Case of Vaginal Leiomyosarcoma
}

\author{
Angel Yordanov ${ }^{*}$, Borislava Dimitrova ${ }^{1}$, Polina Vasileva ${ }^{2}$, Dobromir Dimitrov $^{3}$ and Stanislav Slavchev ${ }^{4}$ \\ ${ }^{1}$ Clinic of Gynecologic Oncology, University Hospital "Dr. Georgi Stranski" -Pleven, Bulgaria \\ ${ }^{2}$ Department of Obstetrics and Gynecology, Medical University, Pleven, Bulgaria \\ ${ }^{3}$ Department of Surgical Oncology, Medical University, Pleven, Bulgaria \\ ${ }^{4}$ Clinic of Gynecology, University Hospital "St. Anna"-Varna, Bulgaria \\ Submission: August 16, 2017; Published: August 28, 2017 \\ *Corresponding author: Angel Danchev Yordanov, Clinic of Gynecologic Oncology, University Hospital "Dr.G. Stranski, Georgi Kochev 8A, Pleven, \\ Post code 5000, Bulgaria, Email: angel.jordanov@gmail.com
}

\begin{abstract}
Introduction: Vaginal Leiomyosarcoma is a rare condition and there is no standard for its treatment. Only 140 cases of this disease have been reported during the past 40 years.

Case report: We report one case of a 35 year old woman with vaginal Leiomyosarcoma.

Results: After a surgery no further treatment was done. There is no evidence of disease for the last forty months.

Conclusion: Vaginal Leiomyosarcoma is an extremely rare disease, which is the reason of the lack of standard treatment. This is why every case of this tumor has to be reported to add more to our understanding of this disease.

Keywords: Vaginal leiomyosarcoma; Surgery; Survival rate
\end{abstract}

\section{Introduction}

Primary malignant tumors of the vagina are extremely rare, accounting for only about $2 \%$ of all gynecologic malignancies. About 140 Leiomyosarcoma in the vagina have been reported during the past 40 years [1]. There are no guidelines or standards established for the treatment of this disease. Vaginal Leiomyosarcoma usually originates from the smooth muscle tissue of the posterior vaginal wall, but they may also develop from smooth muscle cells in tissues near the vagina. This disease is diagnosed only histopatho logically.

\section{Case Report}

A 35 year old woman, gravid 1, para 1, had dysmenorrheal and hypermenorrhoea for 1 year. Because of those complaints she went to gynecologist. She had had an IUD for 6 years. Her medical and surgical history was unremarkable. Gynecological exam and trans-vaginal ultrasound could not be performed because the formation in the vagina deformed it. On the lower anterior wall of the vagina, a round, solid, non-tender mass measuring approximately $10 / 15 \mathrm{~cm}$ in diameter was palpated through the abdomen. The uterine cervix could not be visualized and palpated. The uterine fundus was on the umbilical level. Tran abdominal sonography of the pelvis disclosed a normal uterus and bilateral adnexa and a heterogeneous mass (with liquid zones) measured $120 / 100 \mathrm{~mm}$.

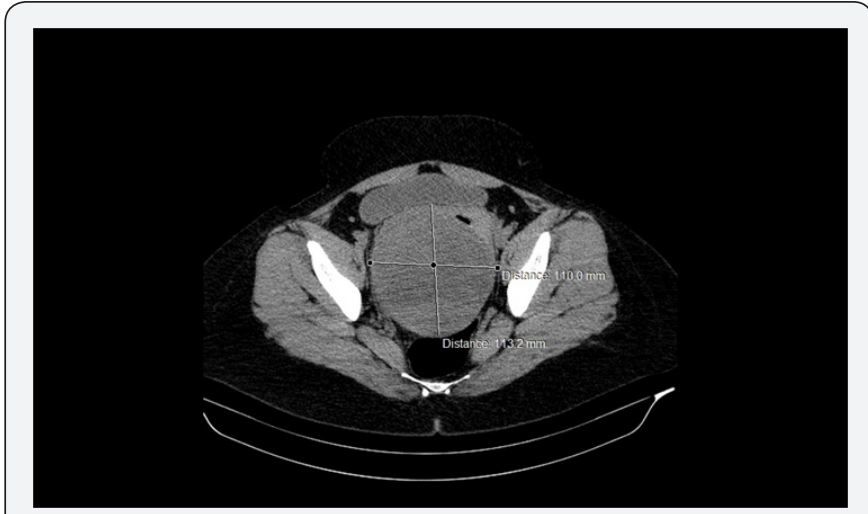

Figure 1: CT scan of the tumor.

A CT of the pelvis and the abdomen was performed. It visualized that the formation is most probably a malignant formation, which arises from the vagina with diameter $110 / 100 \mathrm{~mm}$ (Figure $1 \& 2$ ). The formation appeared to dislocate the entire uterus to the left and in the cranial direction (Figure 3). All laboratory results were unremarkable. When surgery 
was performed the intra operative finding was the following: The uterus was normal in size and shape. The tumor formation was $15 / 10 \mathrm{sm}$, it was located in retroperitoneal, adjacent to the right vaginal wall. The formation appeared to be the reason why the uterus and the urinary bladder were located above the level of the symphysis. The uterine tubes and ovaries, liver and Para-aortic lymph nodes were normal when examined. After the removal of the formation, the uterus and both adnexes were removed and omental biopsy was performed because there were concerns that the formation may be of malignant origin.

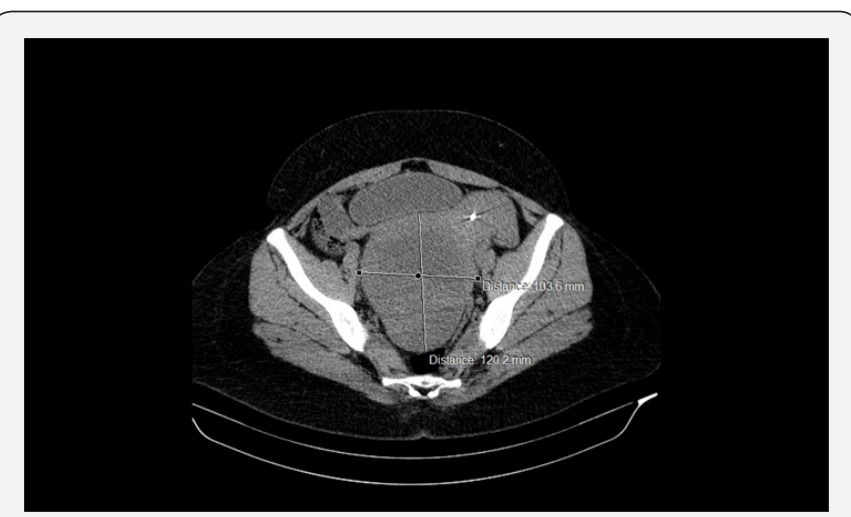

Figure 2: CT scan of the formation and the normal uterus with an intra uterine device in endometrial cavity.

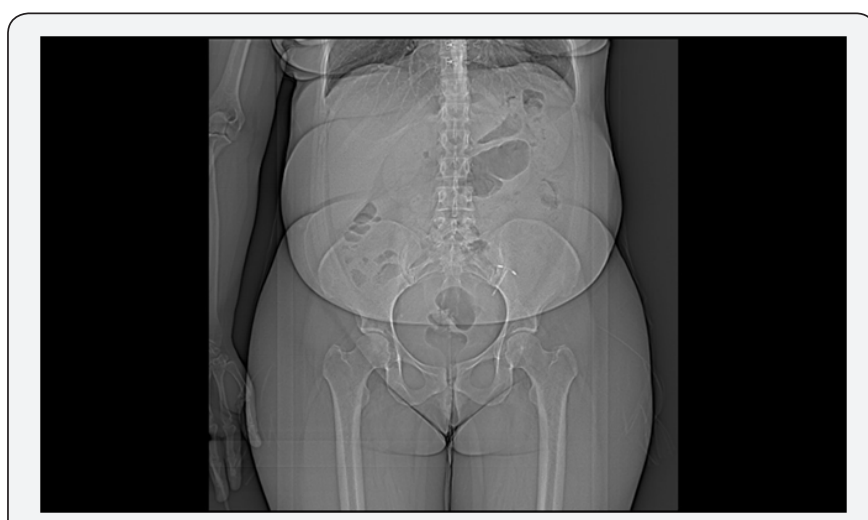

Figure 3: CT reconstruction of the pelvis and abdominal cavity.

The histology was mesenchymal tumor made of polymorphic spindle cells, monstrous cells, PMNs and cells with non- typical mitosis. Ki67 was $36.8 \%$. There were large regions with necrosis. The final diagnosis is high grade Leiomyosarcoma. The patient had routine follow up every three to six months after the operation by CT scans. There is no evidence of recurrence up to this date-three years after the surgical intervention.

\section{Results and Discussion}

Smooth muscle tumors of the vagina are rare but are reported to be the most common benign and malignant mesenchymal formations in adult women. Those tumors may originate from any part of the vagina-benign tumors mostly from the anterior and malignant lesions from posterior vaginal wall, being usually sub mucosal [2]. Leiomyosarcoma is the most common vaginal sarcoma in adult women. There are only 140 cases of vaginal Leiomyosarcoma are reported in the literature, 70 of which are described in articles in English, principally consisting of few case reports and small case series [1-7]. Most sarcomas arise de novo. It is still debated about the possibility of malignant transformation from leiomyoma to Leiomyosarcoma Miyakawa et al. [7] have described that the sarcomata's degeneration of a leiomyoma of the uterus occurs in less than $1 \%$ of all cases. Most patients with vaginal Leiomyosarcoma present with no symptoms, but may also have vaginal, rectal or bladder pain, vaginal discharge or bleeding, difficulty in micturition or dyspareunia [8]. The vaginal Leiomyosarcoma as any sarcoma spreads by local invasion, hematogenous metastasis and has a chance of local recurrence. The average age at diagnosis is about 50 years (from 21 to 86). The 5 year survival rate is $43 \%$ according to Ciaravino et al. [3] Unlike the classical understanding about malignant pathology, in the same study the younger age is demonstrated to be associated with a better prognosis with no notable difference in overall survival between patients who had undergone surgery followed by adjuvant radiotherapy and/or chemotherapy and patients who had been treated with surgery alone [3].

Differential diagnosis of these vaginal masses include Gartner's cyst, granuloma, epithelial inclusion cyst, neurofibroma, rhabdomyoma, capillary hemangioma, squamous epithelial carcinoma, adeno-carcinoma, rhabdomyosarcoma, melanoma, small cell carcinoma, and primary malignant tumors such as mixed müllerian sarcoma that can develop in the vagina. [8] There are still very little cases with vaginal sarcomas. This makes the role of adjuvant radiotherapy and chemotherapy for the overall survival rate unclear. Radical surgery is the main method used for treatment. Our data is in accordance with these 35 years old patient was with high grade vaginal Leiomyosarcoma and refused the adjuvant treatment. In spite of this, she is alive and with no evidence of recurrence three years after the surgical intervention.

\section{Conclusion}

Vaginal Leiomyosarcoma is an extremely rare disease, which is the reason of the lack of standard treatment. This is why every case of this tumor has to be reported to add more to our understanding of this disease.

\section{References}

1. Ahram J, Lemus R, Schiavello HJ (2006) Leiomyosarcoma of the vagina: case report and literature review. Int J Gynecol Cancer 16(2): 884-891.

2. Peters WA, Kumar NB, Andersen WA, Morley GW (1985) Primary sarcoma of the adult vagina: a clinicopathologic study. Obstet Gynecol 65(5): 699-704.

3. Ciaravino G, Kapp DS, Vela AM, Fulton RS, Lum BL, et al. (2000) Primary Leiomyosarcoma of the vagina. A case report and literature review. Int J Gynecol Cancer 10(4): 340-347.

4. Moller K, Mathes GL, Fowler W (2004) Primary Leiomyosarcoma of the vagina: A case report involving a TVT allograft. GynecolOncol 94(3): 840-842. 
5. Ben Amara F, Jaouadi M, Jouini H, Nasr M, Malek M, et al. (2007) Primary Leiomyosarcoma of the vagina. Case report and literature review. Tunis Med 85(1): 68-70.

6. Suh MJ, Park DC (2008) Leiomyosarcoma of the vagina: A case report and review from the literature. J Gynecol Oncol 19(4): 261-264.
7. Miyakawa I, Yasuda H, Taniyama K, Mori R, Uehara Y, et al. (1985) Leiomyosarcoma of the vagina. Int J Gynaecol Obstet 23(3): 213-216.

8. Khosla D, Patel FD, Kumar R, Gowda KK, Nijhawan R, et al. (2014) Leiomyosarcoma of the vagina: A rare entity with comprehensive review of the literature. Int J of Appl Basic Med Res 4(2): 128-130.
Your next submission with Juniper Publishers will reach you the below assets

- Quality Editorial service

- Swift Peer Review

- Reprints availability

- E-prints Service

- Manuscript Podcast for convenient understanding

- Global attainment for your research

- Manuscript accessibility in different formats ( Pdf, E-pub, Full Text, Audio)

- Unceasing customer service

Track the below URL for one-step submission https://juniperpublishers.com/online-submission.php 